\title{
Massive Calcified Cerebellar Pilocytic Astrocytoma with Rapid Recurrence : A Rare Case
}

\author{
Fatih Aydemir, M.D., ${ }^{1}$ Ozgur Kardes, M.D., ${ }^{1}$ Fazilet Kayaselçuk, M.D., ${ }^{2}$ Kadir Tufan, M.D. ${ }^{1}$ \\ Departments of Neurosurgery, ${ }^{1}$ Pathology, ${ }^{2}$ Baskent University Training and Research Hospital, Adana, Turkey
}

Pilocytic astrocytomas (PAs) are World Heath Organization Grade I tumors and are most common in children. PA calcification is not a common finding and has been reported more frequently in the optic nerve, hypothalamic/thalamus and superficially located cerebral tumors. We present a cerebellar PA in a 3-year-old male patient with cystic components and massive calcification areas. The residual tumor grew rapidly after the first operation, and the patient was operated on again. A histopathological examination revealed polar spongioblastoma-like cells. Massive calcification is not a common feature in PAs and can lead to difficulties in radiological and pathological differential diagnoses.

Key Words : Calcification · Pilocytic astrocytoma · Polar spongioblastoma.

\section{INTRODUCTION}

Pilocytic astrocytomas (PAs), which are most common in children, are World Heath Organization Grade I tumors with a good prognosis. This neoplasm can occur at all levels of the neuraxis but occurs most frequently in the cerebellum and the optic pathways ${ }^{2)}$. Calcification in PAs is not a common finding and is reported more frequently in the optic nerve, hypothalamic/thalamus and superficially located cerebral tumors ${ }^{9}$. Massive calcification is extremely rare, and the treatment modality for PAs is surgery; the recurrence rate after total excision is very low. The recurrence time can be as long as four or five years even in the case of residual tumors ${ }^{7}$. Here, we present a case of cerebellar PA with polar spongioblastoma-like cells revealed upon histopathological examination. This PA had massive calcification and a rapid recurrence rate from the residual tumor that led to re-operation.

\section{CASE REPORT}

A three-year-old male patient presented complaints of vomiting and imbalance that had been present for approximately three months. The patient's personal history was normal. A neurological examination revealed cerebellar tests that were impaired. A computerized tomography $(\mathrm{CT})$ examination revealed triventricular hydrocephalus and a left cerebellar mass with hypodense cystic components surrounded by hyperdense area. Magnetic resonance imaging (MRI) revealed a lesion, approximately $6 \times 4.5 \mathrm{~cm}$ in size with cystic central part and peripheral contrast enhancement, which was hypointense on T1-weighted images and heterogeneously enhancing on T2-weighted images (Fig. 1). The tumor was accessed by left suboccipital craniectomy following an external ventricular drainage catheter being placed in the right lateral ventricle. The cystic tumor components were evacuated, and the solid part, which had a gray-white color with moderate vascularity and minimal stiffness and could not be clearly distinguished from the normal parenchyma, was excised with the help of an ultrasonic aspirator. No neurological deficit was observed post-operatively. A microscopic examination revealed diffuse calcification in the tumor tissue. The tumor had a biphasic pattern with pilocytic cells and oligo-like cells in the focal areas; no necrosis or mitotic figures were observed. No EMA staining was seen, and the tumor cells were diffusely stained positive for GFAP. The Ki67 index was less than 1\% (Fig. 2). PA, oligodendrogliom and diffuse astrositoma were considered in differential diagnoses. The age of the patient, the localization of the tumor, the lack of mitosis and necrosis that was indicative of high-grade tumors and the focal biphasic and pilocytic features hinted at PA with massive calcifications. Residual calcified areas were found on post-operative

- Received : December 17, 2014 • Revised : August 4, 2015 • Accepted : August 6, 2015

- Address for reprints : Fatih Aydemir, M.D.

Departments of Neurosurgery, Baskent University Training and Research Hospital, Adana Uygulama ve Arastirma Hastanesi Dadaloglu Mahallesi. 39. Sokak No : 6 , Adana 01250, Turkey

Tel : +90-322-327-27-27, Fax : +90-322-327-12-73, E-mail : md.fatihaydemir@gmail.com

- This is an Open Access article distributed under the terms of the Creative Commons Attribution Non-Commercial License (http://creativecommons.org/licenses/by-nc/3.0) which permits unrestricted non-commercial use, distribution, and reproduction in any medium, provided the original work is properly cited. 

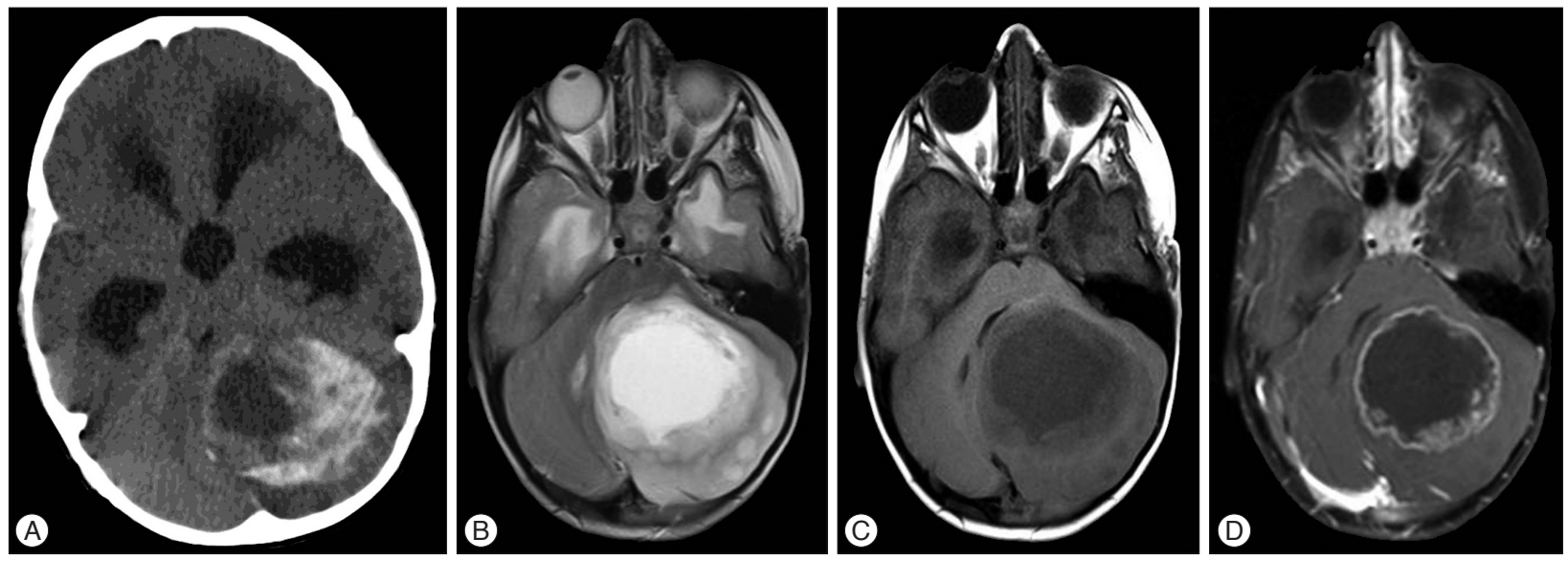

Fig. 1. Preoperative radiological findings. A : Preoperative CT demonstrated cystic, peripheral enhancing calcified lesion. B : Axial T2-weighted MRI demonstrated cystic heterogeneously mass with peripheral edema. C : Axial T1-weighted MRI demonstrated hypodense cystic mass. D : Post-contrast axial T1-weighted MRI demonstrated peripheral contrast enhancing mass.
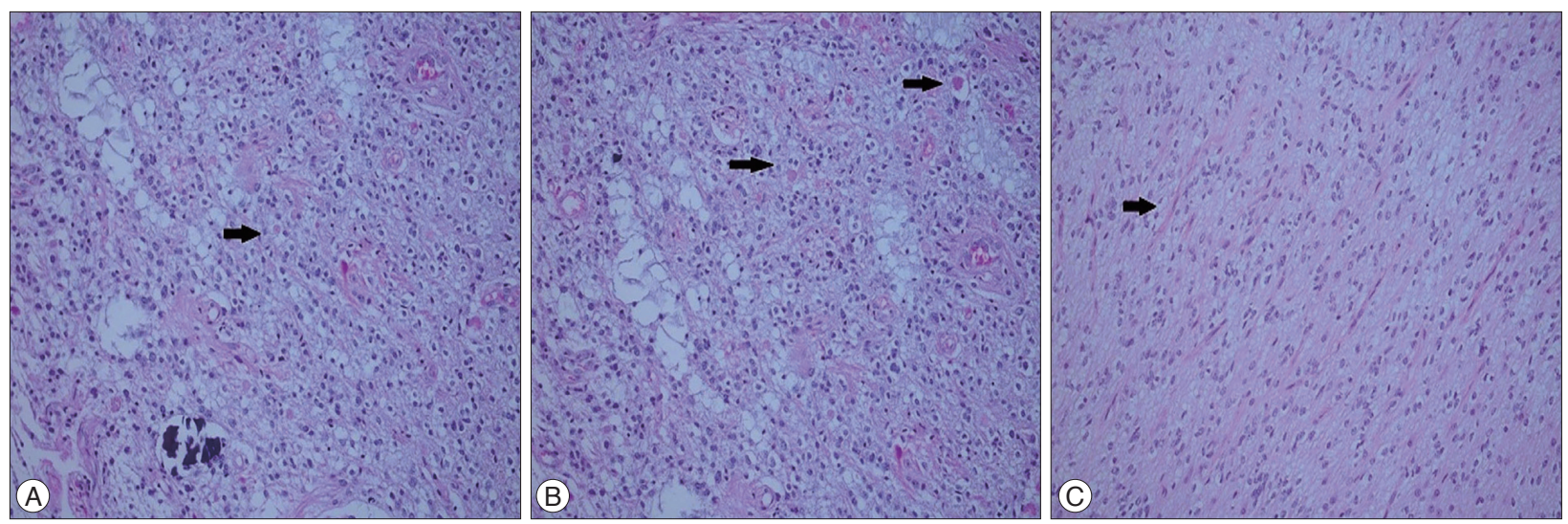

Fig. 2. Pathologic findings after first operation. A : Rare eosinophilic bodies reveal adjacent to calcification (arrow) (H\&E $\times 200)$. B : Eosinophilic bodies and biphasic pilocytic areas (arrows) (H\&E $\times 200)$. C : Rosenthal fibers and biphasic dense areas of the tumor (arrow) $(H \& E \times 200)$.
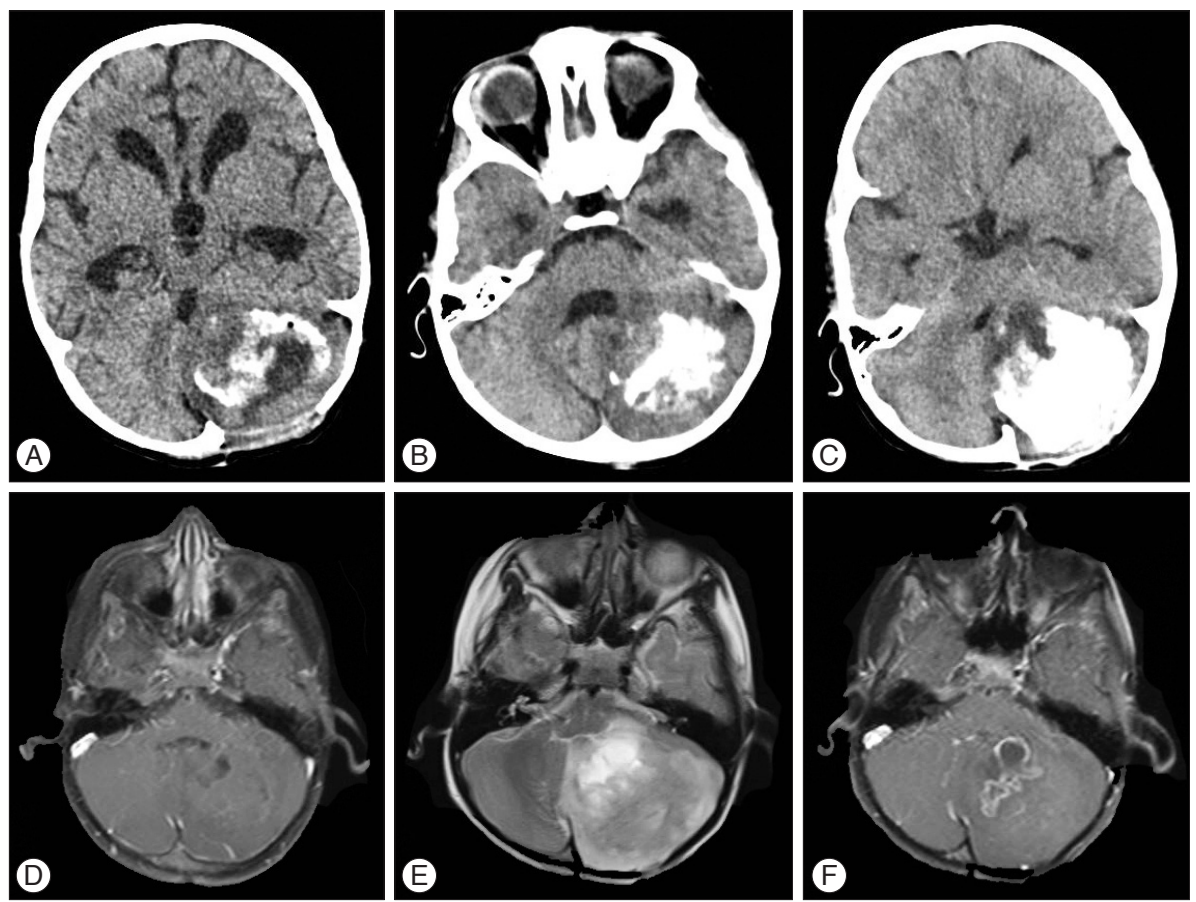

Fig. 3. CTs and MRI showing residual calcified tumor growth. A : Post-operative CT on first day. B : Post-operative CT on 6-month. C : Post-operative CT on 12month. $\mathrm{D}$ : There is no contrast enhancing area on the 6-month axial post-contrast T1-weighted MRI. E : T2-weighted MRI revealed cystic and heterogeneous appearance on the 12-month. F : Postcontrast T1-weighted MRI revealed prominent contrast-enhancing regions. 
Fig. 4. Pathologic findings after second operation. A : Areas with palisading sequence and calcification (H\&E $\times 200)$. $B$ : Oligodendroglioma-like cells (H\&E $\times 200$ ).
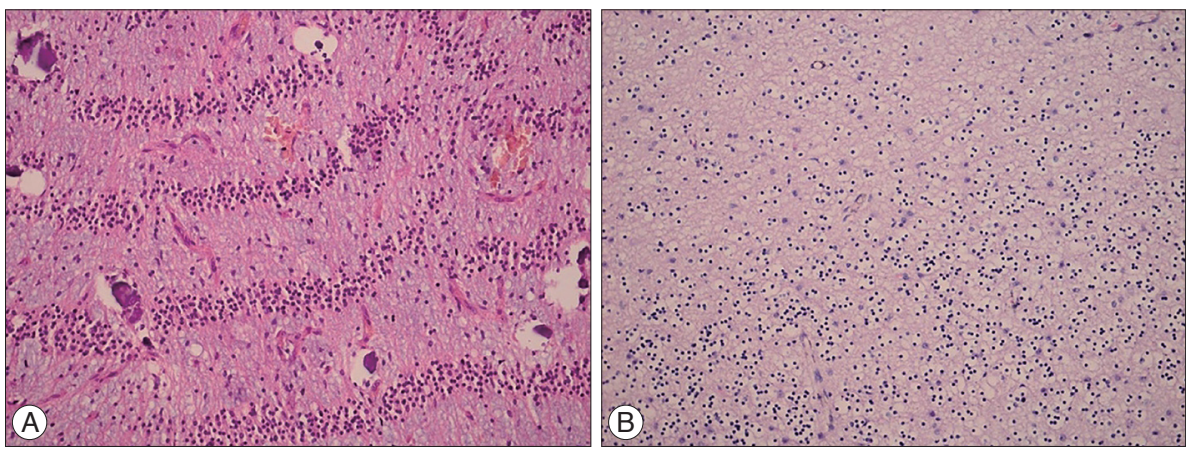

Fig. 5. Tumor pathology was not detected after second operation. A : Axial CT. B : Axial T2-weighted MRI. C : Sagittal T1-weighted MRI.
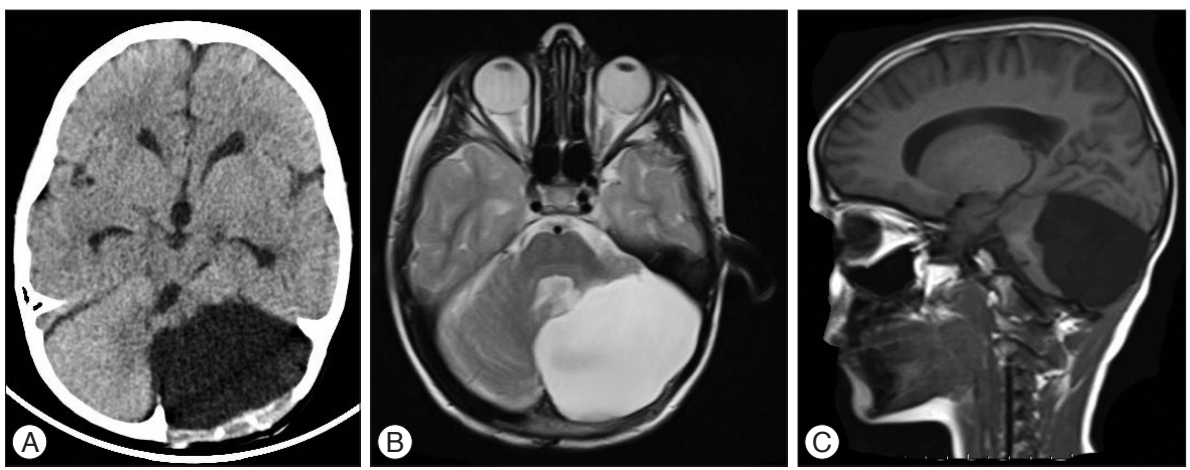

CT scans; no adjuvant therapy was initiated. Post-operative CT and MRI at six months revealed growth of calcified tissue, but no contrast enhancement and perfusion increase was observed. Calcified areas were found to have grown more at the 12-month post-operative CT; areas that showed contrast enhancement were present on the MRI (Fig. 3). The patient who had impaired cerebellar tests received another operation. Macroscopically, the tumor was gray-white in color with moderate vascularity and medium stiffness, and it was totally excised with the help of an ultrasonic aspirator. No neurological deficit was observed postoperatively. A microscopic examination revealed extensive calcification and prominent oligo-like and pilocytic cells as well as the previous tumor. In addition, polar spongioblastoma-like cells with palisadic sequence were detected in the focal areas. GFAP was positive; EMA and NF1 were stained negative. The Ki67 index was less than 1\% (Fig. 4). No adjuvant therapy was initiated. A 1-year control CT and MRI revealed no tumor pathology (Fig. 5).

\section{DISCUSSION}

PAs constitute $56 \%$ of all gliomas. They are the most common gliomas in children and the majority $(67 \%)$ tend to be locate in the cerebellum ${ }^{9)}$. Clinical signs occur due to the compression of the tumor and hydrocephalus. Radiologically, PAs have cystic and solid components. The cystic portion is hypodense on CT, hypointense on T1WI, hyperintense on T2WI, and the solid components are highly enhancinglesions ${ }^{10)}$. The incidence of calcification is approximately $14 \%{ }^{2}$.

Treatment for PAs is surgery; radiotherapy and chemothera-

py treatment can be added for tumors that recur and suffer a malignant transformation. After the total excision of PAs, the 10year survey is $94 \%$, and the 20 -year survey is $79 \%{ }^{10)}$. The most important factor that affects the recurrence rate is tumor excision.

Classical PAs show microscopically biphasic patterns. Rosenthal fibers and bipolar cells constitute the compact part; loose array multipolar cells, microcysts and granular bodies constitute the biphasic view ${ }^{10)}$. Oligo-like cells have been described particularly near the cerebellum. Oligo-like cells rarely have mitosis, hyperchromatic cells, pleomorphism, glomeruloid vascular proliferation and leptomeningeal infiltration, but they do not indicate malignancy ${ }^{1,10)}$.

Diffuse astrocytomas, ganglion cell tumors and pleomorphic xanthoastrocytomas are present in the morphological differential diagnosis of PAs. A pilocytic appearance, a biphasic pattern, Rosenthal fibers and eosinophilic granular bodies are important in the differential diagnosis. However, none of these features are characteristic of PAs. In cases with prominent glomeruloid vascular proliferation, glioblastoma should be kept in mind as a differential diagnosis. The presence of marked oligo-like cells, as in our case, can lead to confusion with oligodendriogliomas. Age, radiological appearance and the presence of the pilocytic pattern, even focal, are important for differential diagnosis. The term "primitive polar spongioblastoma" is used for tumors not included in the new WHO classification and composed of cells with a specific palisading sequence. This pattern can be seen in PAs (e.g., the second resection specimen of our patient) ${ }^{4)}$. Tihan and Burger ${ }^{13)}$ have defined pilomixoid astrocytoma, which is an aggressive subtype of PAs. Pilomyxoid astrocytoma is typically seen in early childhood; most cases settle in the chiasm and hy- 
pothalamic region and metastasis through recurrence and cerebrospinal fluid is high. Necrosis and Ki67 index is higher, and no calcification is observed ${ }^{2}$.

Calcification mechanisms in central nervous system tumors are not fully understood. The reduced metabolism of degenerative tissue stops carbon dioxide production, and the lesion becomes more alkaline than the surrounding tissues as a result. Additionally, increased alkaline phosphatase in degenerative tissues leads to pathologic mineralization such as dystrophic calcification $^{9)}$. Calcification develops slowly over time ${ }^{12}$. Benign and slowly growing glial tumors exhibit calcifications most frequently. The rate of calcification in glial tumors ranges from $9.3-19 \%{ }^{3,5,8)}$. Diffuse, low-grade astrocytomas demonstrate calcifications most frequently among gliomas. Up to $25 \%$ of PAs have intratumoral calcification ${ }^{6)}$. Three intraventricular PA cases with massive calcification have been reported in the literature, but no case involving the cerebellar region has been published ${ }^{9,11)}$.

Massive calcified PA cases in the literature include patients ages 7, 15, and 58 years; our case involved a 3 year old, which we believe is an early age for massive calcification. In our patient, the residual calcified areas began to grow in the third month; cystic and contrast-enhancing solid components with giant calcification emerged again at the end of the patient's first year. Normally; calcification and recurrence development can take long period of time. The rapid growth of the calcified component within one year is interesting. It takes $4-5$ years for recurrence to occur even after partial resection, which is interesting in terms of a pathology such as PA.

\section{CONCLUSION}

As a result, extensive massive calcification is not a common feature of PAs, and it can lead to difficulties in radiological and pathological differential diagnoses. The gross total excision of PAs, including calcified areas, is important to prevent recurrence. Patients whose tumors cannot be totally excised should be followed closely for recurrence.

\section{References}

1. Burger PC, Scheithauer BW, Paulus W, Szymas J, Giannini C, Kleihues P : Pilocytic astrocytoma in Kleihues P, Cavenee W (eds) : Pathology and genetics of tumours of the nervous system, ed 2. Lyon, France : IARC, 2000, pp45-51

2. Fernandez C, Figarella-Branger D, Girard N, Bouvier-Labit C, Gouvernet J, Paz Paredes A, et al. : Pilocytic astrocytomas in children : prognostic factors--a retrospective study of 80 cases. Neurosurgery 53 : 544 553,2003

3. Friedman JH, Chiucchini I, Tucci JR : Idiopathic hypoparathyroidism with extensive brain calcification and persistent neurologic dysfunction. Neurology 37 : 307-309, 1987

4. Fukushima S, Narita Y, Shinomiya A, Ohno M, Miyakita Y, Okita Y, et al. : A case of unclassified high-grade glioma with polar spongioblastoma pattern. Neuropathology $32: 604-610,2012$

5. Gilbertson EL, Good CA : Roentgenographic signs of tumors of the brain. Am J Roentgenol Radium Ther Nucl Med 76 : 226-247, 1956

6. Halpin S, Kingsley D : Disappearance of cerebral calcification as a sign of tumor growth. AJNR Am J Neuroradiol 14 : 119-122, 1993

7. Heideman RL, Packer RJ, Albright AL, Freeman CR, Rorke LB : Tumors of the Central Nervous System in Pizzo PA, Poplack DG (eds) : Principles and Pediatric Oncology, ed 3. Philadelphia : Lipincott-Raven, 1997, pp663-697

8. Kalan C, Burrows EH : Calcification in intracranial gliomata. Br J Radiol $35: 589-602,1962$

9. Kim YE, Shin HJ, Suh YL : Pilocytic astrocytoma with extensive psammomatous calcification in the lateral ventricle : a case report. Childs Nerv Syst 28 : 649-652, 2012

10. Koeller KK, Rushing EJ : From the archives of the AFIP : pilocytic astrocytoma : radiologic-pathologic correlation. Radiographics 24 : 16931708, 2004

11. Kumar R, Garg K, Kakkar A, Sharma MC : Giant calcified intraventricular pilocytic astrocytoma : a rare entity. Neurol India 62 : 71-73, 2014

12. Okuchi K, Hiramatsu K, Morimoto T, Tsunoda S, Sakaki T, Iwasaki S : Astrocytoma with widespread calcification along axonal fibres. Neuroradiology $34: 328-330,1992$

13. Tihan T, Burger PC : A variant of "pilocytic astrocytoma" - a possible district clinicopathological entity with a less favorable outcome. J Neuropathol Exp Neurol 57 : 500, 1998 